\title{
O Brasil e a OPAQ: diplomacia e defesa do sistema multilateral sob ataque
}

\author{
JOSÉ MAURICIO BUSTANI
}
“(...) se tua pátria conta com um único cidadão, que seja homem de bem, ela não manterá por muito tempo seu mau governante." (Petrarca, "Contra a boa e a má fortuna")

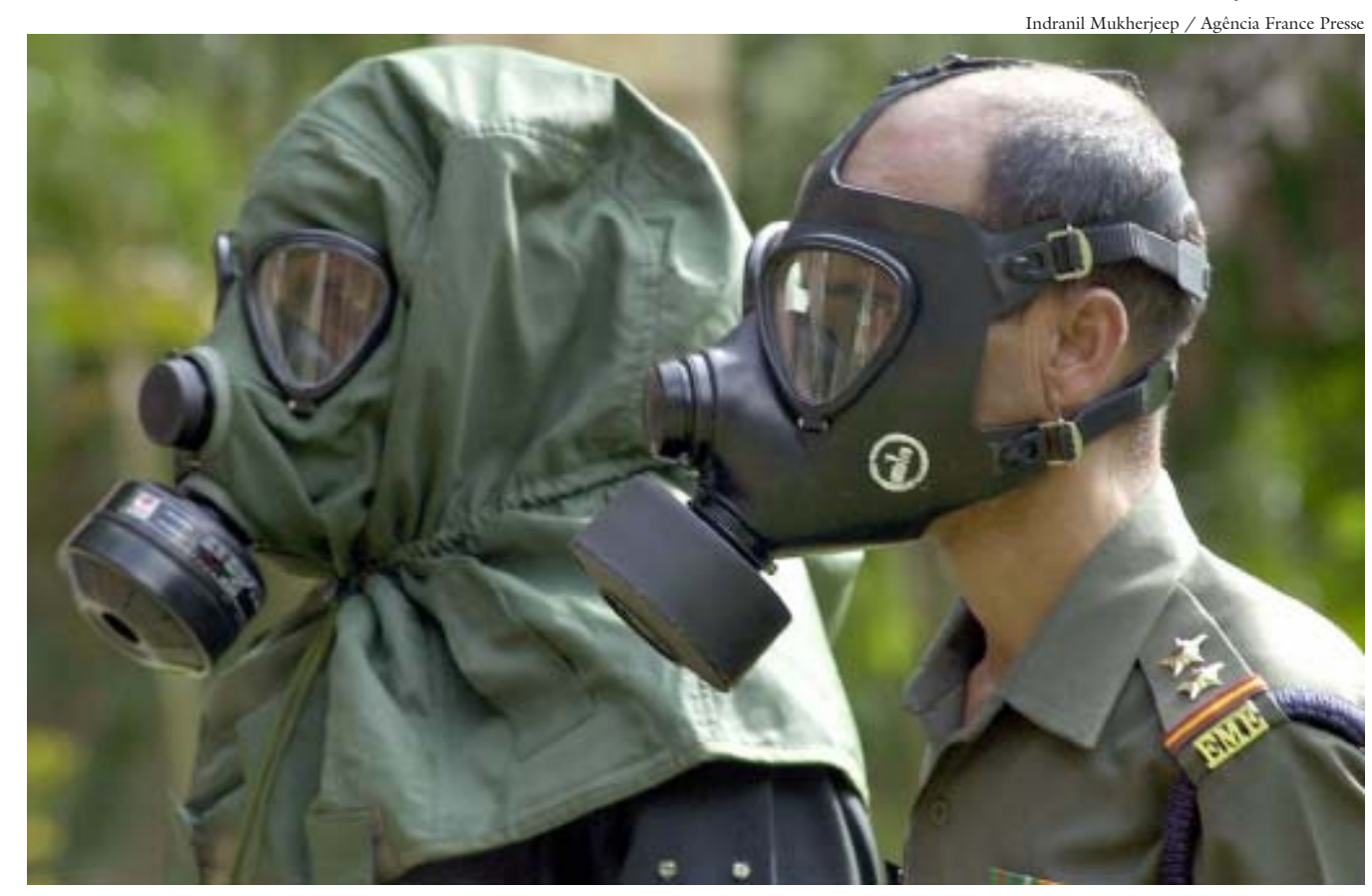

Soldados do Exército indiano vestem máscaras em simulação de defesa de armas químicas

\section{O que é (era!) a OPAQ}

UITO JÁ SE ESCREVEU em revistas especializadas e na imprensa nacional e estrangeira a respeito da Organização para a Proibição das Armas Químicas (OPAQ). Creio ser dispensável, portanto, repetir todo o material didático que normalmente se utiliza para explicar a mais recente e, até há pouco tempo, promissora organização internacional no campo do desarmamento e da segurança. Basta dizer que, politicamente, cabia à OPAQ papel decisivo - no período de transição entre os séculos XX e XXI, como esforço independente, isolado, pioneiro - para "recriar" e "redefinir" o sistema multilateral, sobre o qual grandes mágoas e desilusões pareciam generalizar-se com as dificuldades enfrentadas pelas próprias Nações Unidas nas últimas décadas do século passado. 
Como diretor-geral da Organização para a Proibição das Armas Químicas, nas quais procurava explicar o papel da organização no processo de globalização, pois era minha expectativa que também no campo da segurança internacional o modismo globalizante pudesse prevalecer. Parecia evidente que um tratado multilateral como a Convenção para a Proibição das Armas Químicas (CPAQ) somente poderia favorecer, com o tempo, uma transparência maior dos movimentos internacionais de agentes químicos sujeitos aos mecanismos de verificação da Convenção. Mais importante ainda, a Convenção obriga as autoridades nacionais e outras agências nacionais de implementação a manterem contatos regulares e diretos com suas contra partes em outros Estados membros, de modo a poder conciliar dados e identificar possíveis problemas em seus mecanismos nacionais de monitoramento e troca de informações. Uma semelhante compilação de dados com respeito à implementação de qualquer convenção não seria possível por qualquer país individualmente, fora de um mecanismo jurídico multilateral adequado. Recém nomeado para a chefia da OPAQ, em 1997, cabia-me a responsabilidade de fazer vingar o primeiro tratado abrangente, não-discriminatório e efetivamente verificável por meio de mecanismos internacionais. Nenhum outro tratado multilateral, no campo do desarmamento e da segurança, trazia em seu bojo tantas qualidades e possibilidades e tantos novos recursos de implementação.

Vejamos, então, a seguir, como se frustraram minhas expectativas.

Vale notar que, desde o início de minha missão, insisti no raciocínio de que o conceito de "globalização" deveria necessariamente favorecer, no campo da segurança internacional, um processo multilateral de desarmamento cada vez mais sólido, confiável e abrangente.

O que aconteceu e acontece, lamentavelmente, é que o "multilateralismo", se aplicado ao campo do controle de armas, do desarmamento e da segurança internacional, parece ter-se dissociado do conceito de globalização. Robert Gates, em artigo publicado no New York Times, de 13 de outubro de 1999, já trazia uma clara indicação do que seria a nova reação norte-americana diante da crescente globalização dos instrumentos jurídicos internacionais, quando afirmava que "multilateral treaties often offer only a pretence of effective monitoring" e, mais adiante, que "governments will either not sign it (an international treaty) or, if they sign, will not observe its terms, undermining the legitimacy and value of the arms control process itself".

Não existem textos suficientemente claros a respeito da evolução "política", ou até mesmo jurídica, da OPAQ desde as negociações para sua criação até a efetiva aprovação internacional da Convenção para a Proibição das Armas Químicas. Até mesmo seus "Travaux Préparatoires" deixam muito a desejar.

Faltou registrar com clareza, nesse processo histórico, a ausência de um apoio norte-americano autêntico à concepção não-discriminatória ou, para usar uma expressão mais diplomática, "não-diferenciada" da Convenção, que se propunha ser efetivamente um tratado igualitário, na letra e no espírito.

Explico-me. As negociações que levaram, ao fim de uma década, à adoção da Convenção para a Proibição das Armas Químicas transcorreram, em 1993, com base na premissa de que os Estados Unidos e a Rússia manteriam um regime de inspeção 
separado, bilateral, independente do regime que seria adotado pela Convenção para o resto do mundo. Tal cenário levaria de fato a Rússia a uma posição de nítida e inevitável inferioridade na implementação da Convenção (ela estaria sujeita a um regime de inspeções realizadas pelos técnicos norte-americanos e não por inspetores internacionais) e só pareceu aceitável a Moscou, nos anos imediatamente anteriores à adoção da CPAQ, por conta das crescentes dificuldades econômicas que enfrentava. Os Estados Unidos, segundo o plano inicial, implementariam assim todo um programa de inspeção na Rússia com seus técnicos, fora do controle da OPAQ, "contribuindo" teoricamente para aliviar o ônus "financeiro" da organização. O que não se ousava dizer naquele momento era que, na prática e "na história", excluía-se o foro multilateral de um processo que se qualificava cinicamente de "internacional".

O emprego de armas químicas pelo Iraque na guerra contra o Irã e mais adiante o risco da utilização de tais armas na Guerra do Golfo, precipitaram e facilitaram a conclusão das prolongadas negociações da Convenção para a Proibição das Armas Químicas.

As autoridades de Moscou entenderam, no processo de negociações, que o risco de uma subordinação sua a um regime paralelo ao da Convenção, pelo qual estariam sujeitas unicamente ao escrutínio norte-americano, era muito alto. A urgência política e estratégica daquele momento específico em concluir os trabalhos negociadores e lograr uma convenção a qualquer custo como que passou por cima do tema, havendo-se então chegado a um texto de consenso, aplicável de maneira uniforme a todos os países. E a partir daí cresceram as expectativas idealistas de implementar-se um instrumento decididamente universal e não-discriminatório.

O processo de entrada em vigor da Convenção levou aproximadamente quatro anos (1993-1997). Com importantes qualificações e restrições, o Congresso e o Executivo norte-americanos juntaram-se à CPAQ somente após ter sido alcançado o número de 65 ratificações necessário para que ela entrasse em vigor.

A administração do presidente Clinton foi forçada pela Comissão de Relações Exteriores do Senado a incluir 28 "condições" ou reservas ao texto da CPAQ para que pudesse ser aprovada. Algumas delas constituem um verdadeiro repúdio a cláusulas importantíssimas da Convenção (ver "Rule of Power or Rule of Law?", publicação do "Institute for Energy and Environmental Research and Lawyer's Committee on Nuclear Policy", de abril de 2002, páginas 83, 84 e 85; www.ieer.org ).

A Rússia, por outro lado, não ratificou a Convenção naquele momento, por conta do desconforto e das suspeitas que experimentavam certos círculos em Moscou a respeito de uma ainda possível tentativa de "dualidade" de regimes na prática ou de discriminação na implementação do acordo, por parte das autoridades da Organização e dos Estados membros.

Tornou-se imperativo que o diretor-geral visitasse a Rússia e iniciasse o que seria um longo processo diplomático de "persuasão" do Executivo russo - e, sobretudo, da Duma - fazendo-lhes ver as vantagens da CPAQ.

Em poucas palavras, a Rússia confiou em que o "bilateralismo" que the havia sido proposto no passado não voltaria pela porta dos fundos e que o mecanismo "multilateral" recém estabelecido, com as garantias de respeito integral que lhe em- 
penhei como diretor-geral, constituía o melhor caminho para escapar ao escrutínio direto e específico dos Estados Unidos, que no âmbito da OPAQ pareciam desconhecer o término da guerra fria. Assim, a confiança em que a OPAQ seria efetivamente neutra, independente e não-discriminatória foi responsável pela inclusão da Rússia país possuidor do mais importante arsenal de armas químicas do mundo - no regime da CPAQ, sete meses apenas após sua entrada em vigor. Em 5 de novembro de 1997, a Duma retirava sua oposição ao depósito do respectivo instrumento de ratificação pelo Kremlin.

Se esse foi o entendimento russo, bem distinto foi o norte-americano.

Numerosos países foram, com entusiasmo, aderindo à Convenção ou apressando o processo de sua ratificação, inclusive aqueles como a Índia, o Paquistão, Cuba, tradicionalmente críticos de acordos internacionais iníquos (como o TNP, Tratado de Não-Proliferação de Armas Nucleares, de caráter discriminatório), e naquele momento até mesmo o Brasil. Enquanto isso, os Estados Unidos, mesmo durante a administração do presidente Clinton, nos últimos meses antes da finalização da Convenção, acreditavam que seria possível "adaptar" a OPAQ a seus projetos, interpretações e interesses específicos. Não terá sido, aliás, por outro motivo que favoreceram o estabelecimento da Organização na cidade de Haia, distante dos foros multilaterais tradicionais, como Nova York, Genebra e Viena, onde as representações diplomáticas são devidamente treinadas no delicado trabalho de negociação de acordos, inclusive - e em grande medida - nos temas de desarmamento e segurança.

À exceção de alguns poucos países do primeiro mundo, os demais membros da OPAQ, inclusive o Brasil, deveram contar, desde a fase da Comissão Preparatória da Organização, por falta de recursos orçamentários e de pessoal especializado, com a improvisação de seus agentes diplomáticos em Haia, eminentemente "bilaterais", para desempenhar um trabalho multilateral de extrema complexidade e sensibilidade.

\section{A presença brasileira}

\section{nas organizações internacionais a partir de 1990}

Não há lugar neste contexto para análise da política externa do governo do expresidente Collor, até porque naquele período não houve propriamente uma orientação claramente enunciada sobre as aspirações do Brasil no âmbito externo, muito menos com relação às organizações internacionais. Na verdade, não parecia existir simpatia com relação aos organismos internacionais e, em particular, com relação à presença de brasileiros no corpo administrativo daquelas instituições. Cabe assim registrar que, já em 1990, foi aprovada, por proposta do Executivo e iniciativa da então "Secretaria da Administração Federal", legislação obtusa que penalizava (e ainda penaliza, pois continua em vigor) funcionários públicos brasileiros que sirvam em organismos internacionais.

Enquanto tantos outros países procuram projetar sua imagem através da presença de seus nacionais em cargos de direção ou relevância no âmbito das Nações Unidas ou de organizações internacionais em geral, os sucessivos governos brasileiros da década de 90, à exceção de um breve período sob Itamar Franco, pareceram dedicar ao tema um discreto desprezo, talvez resultado de uma abordagem superficial do assunto. 
Se o governo Itamar Franco, com Celso Amorim na chefia do Itamaraty, mobilizava a opinião pública e os próprios diplomatas para a projeção política internacional que, legítima e necessariamente, se pretendia para o País, as administrações subseqüentes esvaziaram o tema e desmobilizaram o país, revelando-se precocemente exaustas e inibidas pelas dificuldades inerentes ao "trabalho político" e, mais adiante, pela chamada falta de "excedente de poder" (conceito recentemente copiado de má fé do eminente chanceler brasileiro Ramiro Saraiva Guerreiro, que o utilizara originalmente para caracterizar um período completamente distinto de nossa história político-diplomática).

A diplomacia brasileira passou a apostar todo o seu capital político-diplomático no desenvolvimento da capacidade exportadora do país, dimensão deveras importante mas que, tal como implementada, obviamente castrou o potencial que se havia tradicionalmente acumulado, desde os tempos do Itamaraty da Rua Larga, no Rio de Janeiro, na formação de agentes diplomáticos que pudessem "pensar" o País e contribuir para o desenvolvimento e a implementação de uma política exterior destinada a facultar ao Brasil o papel que merece e é capaz de exercer, sem subordinação espúria a imposições arbitrárias de outras potências.

João Clemente Baena Soares, secretário-geral da Organização dos Estados Americanos por dois brilhantes mandatos, terá sido o último representante do Brasil indicado para uma prestigiosa função internacional por verdadeiras razões de Estado. Lamentavelmente, já no início de sua gestão, percebiam-se os primeiros sinais do desinteresse e da falta de apoio político por parte de Brasília.

Daí para frente, o governo brasileiro não pareceu mais inclinado a estimular ou mesmo facilitar a participação de seus funcionários em organismos internacionais. A indicação de meu nome para candidato à diretoria da OPAQ foi uma clara exceção àquela "regra" e deveu-se sobretudo a insistentes propostas da então embaixadora do Brasil em Haia e representante permanente junto à OPAQ e à aquiescência do então ministro, interino, das Relações Exteriores.

Não obstante, durante meus cinco anos na chefia da OPAQ, preferi pensar que o Brasil "acreditava" na Organização e por isso havia submetido o nome de um brasileiro à comunidade internacional que finalmente o elegeu seu primeiro diretorgeral.

Insisti junto ao governo Fernando Henrique Cardoso quanto à importância das enormes oportunidades políticas e econômicas disponíveis para o nosso País, uma das 10 potências químicas mundiais, através da implementação de programas em parceria com a Organização; expliquei as implicações estratégico-políticas da OPAQ às mais altas autoridades brasileiras, quando logrei ser convidado a visitar oficialmente Brasília. Mas como os fatos vieram a confirmar em 2002, eram vãs minhas esperanças ...

\section{Uma concepção da OPAQ do ponto de vista de um diplomata brasileiro}

Acompanhei, por razões de ofício, a evolução final das negociações que levaram ao estabelecimento da OPAQ em 1997. No processo, deixei-me influenciar pela expectativa de que, efetivamente, seria possível construir algo superior ao Tratado de 
Não-Proliferação de Armas Nucleares (TNP), discriminatório por excelência e muito aquém do que sempre entendi por instrumento sério de desarmamento internacional. Acreditei ser possível deixar a "marca" da diplomacia brasileira no empreendimento. Ingenuidade? Talvez... Idealismo? Seguramente. O fato é que, ao ser levado à posição de candidato brasileiro a primeiro dirigente de uma organização internacional do porte da OPAQ, entreguei-me de corpo e alma à concretização do que entendia ser a letra e o espírito da Convenção, na crença de que, para tanto, teria do governo de meu País permanente solidariedade e apoio, a exemplo do que me foi freqüentemente oferecido por muitos outros países grandes, médios e pequenos, membros da OPAQ.

O descaso de algumas autoridades brasileiras de então por tudo o que era relacionado com as Nações Unidas ficou demonstrado no desinteresse em levar adiante a proposta de integrarmos, como membro permanente, o Conselho de Segurança da Organização; na relutância em colaborar "com empenho e arte" no processo de Operações de Paz; e na ânsia por entregar-se, sem qualquer aumento de credibilidade para o País, ao regime discriminatório do Tratado de Não-Proliferação de Armas Nucleares (cuja aceitação nos valeu um simpático tapinha nas costas dos Estados Unidos e de outros defensores do Tratado...). O descaso explica também a ausência de desempenho protagônico do Brasil na OPAQ, na linha do que me havia habituado a aspirar, durante longa carreira na área da diplomacia multilateral.

Por força tanto da letra da Convenção como do papel que a delegação do Brasil havia exercido nas negociações em Genebra, sempre insisti em que a OPAQ era mais que uma organização encarregada do desarmamento químico. Muito mais estava em jogo. Seus idealizadores haviam conseguido, a rigor, criar uma organização internacional de caráter pioneiro e abrangente, com grande responsabilidade na área da cooperação internacional e da luta contra o subdesenvolvimento.

As competências da nova organização no campo da proteção contra ataques com armas químicas (ainda que limitada na prática a certas conjunturas geopolíticas) e, sobretudo, as competências na área da promoção do desenvolvimento das indústrias químicas para fins pacíficos em países em desenvolvimento, exigiam do diretorgeral, e mormente de um diretor-geral brasileiro, uma dedicação especial.

O artigo 11 da Convenção, relativo à cooperação internacional para a promoção da química para fins pacíficos, existia, afinal de contas, graças à arte, à habilidade e à visão da delegação brasileira nas negociações em Genebra, a quem se confiou a missão de obter um texto de consenso sobre o assunto, de dificílimo equilíbrio político, mas que viabilizou a adoção da convenção por países que, de outra forma, a ela teriam destinado o mesmo tratamento que ao TNP.

Como diretor-geral, procurei insistentemente estabelecer mecanismos que permitissem o desenvolvimento de programas palpáveis de cooperação internacional, apesar dos limitados recursos orçamentários destinados à matéria.

Para alguns países desenvolvidos, em particular os Estados Unidos, era difícil o convívio com os princípios do artigo 11, dos quais só faziam uma leitura negativa, como se fosse uma válvula de escape para que governos "pouco confiáveis" se aproveitassem de programas de cooperação técnica para a fabricação de armamentos quí- 
micos. A meu ver, esta atitude era a negação mesma da validade e da eficácia da Convenção e comprovava, na verdade, que o instrumento autenticamente jurídico, negociado multilateralmente, não era visto, por parte daqueles países, com a mesma confiança que os chamados "regimes informais", particularmente o do "Grupo da Austrália" no caso das armas químicas, resultantes de arranjos políticos e implementados segundo critérios desprovidos de qualquer base jurídica mas, seguramente, fundados em percepções e interesses específicos, embora coincidentes, de seus membros e de legitimidade pelo menos discutível.

Nada disso contribuía, obviamente, para desenvolver e fortalecer o regime da OPAQ. Ao contrário, a situação acima descrita dificultava seriamente meu esforço ademais, minha obrigação, como diretor-geral - de trazer para o seio da Convenção aqueles países, em particular do mundo em desenvolvimento, desprovidos até de qualquer indústria química, que ainda buscavam boas justificativas para participarem do esforço internacional que se ia montando, na forçada calada da noite, na cidade de Haia.

Terá sido minha maior vitória, no campo da cooperação internacional, a concretização de um projeto pioneiro que se convencionou chamar de "Associate Programme".

A despeito do apoio quase inexistente dos países responsáveis pela maior parcela do orçamento da Organização, consegui atrair outros importantes membros da OPAQ, como o Reino Unido e o Canadá, para um entendimento maduro da importância econômica e política de programas de tal natureza. O programa consiste no treinamento, no seio da OPAQ, de especialistas químicos de países em desenvolvimento, seguido de aperfeiçoamento em centros universitários e científicos de países desenvolvidos, culminando com estágios em estabelecimentos industriais químicos sofisticados, em países dotados de importante indústria química (durante meu mandato, apenas em países da União Européia, mas com perspectivas promissoras alhures), onde os bolsistas participantes eram expostos a novas técnicas de administração de empresas e, naturalmente, a conhecimentos avançados nas áreas de sua especialização. Ao retornarem a seus países de origem, estariam mais aptos a contribuir para a construção ou reconstrução de indústrias na área de fertilizantes, pesticidas e medicamentos, entre outras, de inegável relevância para o progresso e bem-estar de suas populações.

Esforços desta natureza terão certamente contribuído para o impressionante crescimento do número de membros da OPAQ. Em 1997, eram 87 os países que dela participavam. Quando de meu afastamento, e abril de 2002, já havia 145 Estados membros. Teríamos certamente obtido até maior êxito se eu pudesse ter contado com a compreensão e o apoio político efetivo dos Estados Unidos e de outros países política e economicamente influentes.

No âmbito latino-americano, não obtive a colaboração do governo brasileiro, cuja ajuda solicitei com insistência, com vistas a construir ativamente o que seria a primeira "zona livre de armas químicas”, a partir do capital diplomático e do prestígio natural do Brasil na região. Sobram, assim, fora do regime da CPAQ, alguns poucos países do Caribe e da América Central que, de outra maneira, teriam possibi- 
litado à América Latina arvorar-se mais uma vez em exemplo, como no caso do Tratado de Tlatelolco, de responsabilidade internacional e contribuição para a construção de um mundo de paz e segurança. Tampouco logrei, no âmbito do que se chama a "Comunidade dos Países de Língua Portuguesa", o necessário suporte brasileiro para permitir, durante meu mandato, passos importantes em direção à universalização da Convenção para a Proibição de Armas Químicas.

\section{Cinco anos de lutas e vitórias}

Estive à frente da OPAQ por cinco anos, ao final dos quais fui afastado, sem qualquer base jurídica, por iniciativa dos EUA, pouco antes de completar o primeiro ano de meu segundo mandato, sob a alegação, em bases informais, de má gestão e, oficialmente, de "perda de confiança" por parte dos maiores contribuintes financeiros. Fui afastado apesar dos apoios que recebi pessoalmente dos representantes permanentes junto à OPAQ que admitiam encontrarem-se seus governos sob extrema pressão norte-americana, inclusive com ameaça dos Estados Unidos de suspenderem qualquer pagamento de suas dívidas para com a Organização.

Permito-me citar aqui, para efeitos de esclarecimento e para assinalar a ausência de veracidade das alegações norte-americanas quanto à minha gestão, o simpático mas constrangedor discurso do presidente da Conferência Especial da OPAQ (21 de abril de 2002), convocada, por iniciativa norte-americana, para "cumprir as instruções de Washington" e demitir-me do cargo. Disse Heinrich Reimann, embaixador da Confederação Helvética: "I thank the outgoing Director-General for his many years of dedicated service to the Organisation. Under Mr. Bustani's leadership, this organisation has become one of the foremost multilateral disarmament organisations, setting standards of excellence and equal treatment".

Desde o começo de meu mandato fiz uma opção clara. Lutando contra a falta de apoio financeiro, contra o ainda reduzido número de Estados membros e, mais ainda, contra a aparente falta de entendimento internacional do que se estava criando em Haia e a atitude do governo norte-americano - inicialmente relutante e depois terminantemente negativa - optei por salientar e fazer valer o caráter multilateral da Organização, como único mecanismo capaz de organizar internacionalmente as questões relativas ao desarmamento químico e à segurança internacional. Acreditava que o êxito de tal empreendimento levaria a que fosse ele seguido por outras iniciativas do mesmo porte, fortalecendo assim a rede de instrumentos multilaterais para a construção de uma ordem internacional melhor.

Douglas Scott, presidente do "Canadian Markland Group for the Integrity of Disarmament Treaties", escrevia em 21 de abril de 2002, a propósito da campanha norte-americana para me remover da direção da OPAQ que "... At stake is the multilateral nature of the machinery used for monitoring compliance with the Convention. The multilateral element is essential in order to ensure that the verification rules and procedures are applied equally to all member States with no preferential treatment".

Em artigo no jornal The Guardian, de Londres, em 16 de abril de 2002, George Monbiot já descrevia a estratégia norte-americana para afastar-me da chefia da OPAQ como "um golpe para destituir o homem encarregado de livrar o mundo das armas químicas”. Dizia Monbiot: “... se os EUA forem bem sucedidos, terá sido a primeira 
vez que o chefe de uma organização internacional é deposto desta maneira. Os demais organismos internacionais ficarão vulneráveis a ataques semelhantes. O golpe também bloqueará as opções pacíficas para lidar com as armas químicas que o Iraque pode ainda possuir, fortalecendo o argumento de que a guerra é o único caminho para destruí-las".

Inclui os textos acima porque salientam os aspectos principais de minha gestão à frente da OPAQ, aspectos que foram usados pelos Estados Unidos, para proceder à destituição de um brasileiro que ocupava o cargo mais elevado que já coube ao Brasil na história das organizações internacionais. São eles:

- o tratamento não-discriminatório que dei a todos os Estados membros no âmbito da CPAQ;

- o apoio insistente que reivindiquei de todos os Estados membros para a OPAQ, que, junto com outras instituições multilaterais, me parecia o único caminho legítimo para regular a vida entre as nações;

- a busca permanente de soluções pacíficas para controvérsias, inclusive através do oferecimento dos préstimos da organização para, em cooperação com outros organismos internacionais (como o Conselho de Segurança das Nações Unidas, no caso específico do Iraque), evitar-se a possibilidade de conflitos de conseqüências inimagináveis.

Devo dizer que a relação com a delegação dos Estados Unidos, nos primeiros quatro anos de minha gestão, se não foram intoleráveis, tampouco foram um mar de rosas.

Frustrados com o abandono do viés bilateral e independente que sempre imaginaram para sua relação com a Rússia na área de armas químicas - e "vitimados" por minha insistência em aplicar a todos igualmente o regime da Convenção, sem qualquer tratamento preferencial - desde cedo buscaram motivos para desestabilizarme. Apesar disso, e, de certa forma, surpreendentemente, entre 1997 e 2001, à exceção de Madeleine Albright, os demais membros da administração em Washington - Defesa e Comércio em particular - terão sido, talvez até a contragosto, responsáveis por minha permanência tão longa na chefia da OPAQ.

Atribuo em particular ao Pentágono a iniciativa e o encaminhamento de minha reeleição um ano antes do fim de meu primeiro mandato, em entendimento com as autoridades responsáveis pela OPAQ em Moscou. Terá havido, naquele momento, a conscientização, por parte da administração democrata, de que os interesses norte-americanos, ainda que freqüentemente por mim contrariados na prática, não o eram a ponto de justificar que se sacrificasse a implementação da Convenção erga omnes, em benefício do fortalecimento do sistema multilateral dentro do que era então possível.

Não terá sido, quero ainda crer, por outro motivo que o Secretário de Estado Colin Powell, nos seus primeiros dias à frente do Departamento de Estado, em carta que me dirigiu, em $1^{\circ}$ de fevereiro de 2000 , afirmava que “...the accomplishments to date of the OPCW are very impressive. They reflect well on the commitments of States Parties to fulfill their mandate to rid the world of chemical weapons and on 
the dedication and hard work of the staff of the Technical Secretariat under your leadership".......The United States actively supports your efforts to pursue universal application of the Convention.... The US stands ready to work with you, the Technical Secretariat and other Member States, in developing a plan of action to address current cash-flow difficulties and to put the Organisation on a more financially sound foundation..." Aí está o reconhecimento explícito do problema financeiro que enfrentou a OPAQ, desde 1998, em grande parte devido ao "contraditório" comportamento dos Estados Unidos, não só por obstaculizar as negociações sobre orçamento, mas também por deixar de efetuar, em tempo hábil, o pagamento de suas contribuições financeiras.

O fato é que a frustração norte-americana tendia a crescer, em virtude de minha insistência em negar tratamento preferencial aos Estados Unidos na aplicação da Convenção, seja com relação às inspeções militares, seja com relação às inspeções industriais, aquelas acompanhadas pelo Pentágono e estas pelo Departamento de Comércio, sob a coordenação única do Departamento de Estado.

Incomodavam Washington também minha resistência a admitir interferências com a administração financeira e de pessoal da OPAQ (o que haviam podido fazer durante a Comissão Preparatória), minha recusa a dar a seus representantes em Haia acesso a informações referentes a outros membros da organização, fora dos mecanismos previstos pela Convenção. A propósito, lembro-me ainda da surpresa demonstrada por colega titular de organização internacional assemelhada, quando the assegurei que não dispunha de mecanismos para compartilhar com certos países "selecionados" informações "específicas" a respeito de outros Estados membros - o que aliás pensei ser a prática também em outros organismos.

Com o pleno estabelecimento da administração republicana nos Estados Unidos e a investidura de alguns de seus agentes mais ideológicos, percebi que o processo de minha "desconstrução" havia começado... Em junho de 2001, John Bolton, subsecretário para Assuntos de Desarmamento do Departamento de Estado, me telefonaria para tentar interferir, em tom ameaçador, em decisões de exclusiva responsabilidade do diretor-geral.

Enquanto isso, a Rússia, inicialmente duvidosa em ratificar a Convenção, como expliquei acima, "surpreendia-se" favoravelmente com a correção e a neutralidade da conduta que imprimi à Organização. Como resultado de minhas muito freqüentes pressões pessoais para que Moscou implementasse impecavelmente o regime da CPAQ, a Rússia tornou-se, com o tempo, um dos países membros que mais se esforçaram em cumprir com os requisitos da Convenção e apoiar os trabalhos da OPAQ.

Ao mesmo tempo, os países em desenvolvimento, embora limitados em sua atuação em Haia pelo simples fato de ser reduzida sua representação diplomática e pela complexidade temática da OPAQ, foram-se unindo pouco a pouco a meus esforços, ao descobrirem todo o potencial que se lhes oferecia em matéria de cooperação internacional e proteção contra o uso ou ameaça de uso de armas químicas.

\section{Os republicanos e a OPAQ}

Ian Williams, na publicação Foreign Policy in Focus, em 30 de abril de 2002, com grande lucidez escrevia que "...Quietly, and without the fanfare that accompanies 
the campaign in the mountains of Afghanistan, the administration has begun a long march through multilateral institutions. At the United Nations and elsewhere, the United States has mounted a campaign to purge international civil servants judged to be out of step with Washington in the war on terrorism and its insistence that the US have the last word in all global governance issues. The first and foremost prominent to go was Mary Robinson, the former Irish President... Another recent victim of the US campaign was Robert Watson, the much-respected chair of the Intergovernmental Panel on Climate Change... A few days later, on April 22, the US right achieved a new level of success with the deposition of José Mauricio Bustani, the head of the OPCW, a mere year after he had been unanimously elected for a second four-year term... Bustani, a Brazilian, has headed it from its creation five years ago and his inspectors have overseen the destruction of two million chemical weapons and two-thirds of the world's chemical weapons facilities in the past several years. They have carried out 1100 inspections in more than 50 nations. From the beginning of 2002, however, the United States has treated Bustani almost as if he were some form of bureaucratic Bin Laden..."

Impressionou-me a percepção de Williams sobre meu caso específico porque, mesmo sendo ele um estudioso na matéria, era um observador à distância, com quem jamais tive qualquer contato. Fica seu testemunho de que, ao contrário do que procuraram provar os americanos, eu não havia mudado. Mudou Washington, com a chegada dos republicanos.

Williams menciona ainda, mais adiante, o que terá sido um das causas mais profundas de meu afastamento, a saber, a questão da possível adesão do Iraque à OPAQ e a conseqüente aceitação por Bagdá do regime de inspeções da Organização, o que poderia eventualmente romper o impasse que enfrentavam as Nações Unidas desde 1998.

Tivesse o Iraque seguido mais rapidamente os passos do Irã, do Paquistão e do Sudão, que aderiram à CPAQ durante o meu primeiro mandato, e até mesmo da Líbia (que chegou a anunciar a sua adesão à CPAQ semanas antes do início da campanha norte-americana contra mim), é possível que meus esforços diplomáticos tivessem logrado importantes êxitos no Oriente Médio latu sensu e permitido a retomada, em cooperação com as Nações Unidas, como era minha proposta, da implementação do regime de inspeções determinado pelo Conselho de Segurança para Bagdá.

Mas provavelmente desapareceriam naquele momento os argumentos para justificar o que está acontecendo enquanto escrevo esta matéria, em novembro de 2002: a preparação de uma ação militar contra o Iraque por parte de Washington, antes de que se tivessem esgotado todos os mecanismos pacíficos previstos no Direito Internacional.

Não me resta dúvida de que, a despeito de uma possível boa disposição inicial por parte de Colin Powell, o crescimento na administração republicana de outros atores, mais comprometidos ideologicamente com um passado que se recusam a ver superado - Dick Cheney, Donald Rumsfeld e John Bolton em particular - levou a uma revisão definitiva do que se esperava em Washington das instituições multila- 
terais. E as vítimas se foram acumulando nas figuras do Protocolo de Kyoto, do Protocolo à Convenção para a Proibição de Armas Biológicas, do Estatuto de Roma, que estabeleceu o Tribunal Penal Internacional, e da própria OPAQ, na pessoa de seu diretor-geral, que insistia na implementação eficaz e absolutamente independente do único regime confiável de desarmamento e não-proliferação.

A atual administração de Washington parece só aceitar compromissos internacionais na medida em que os possa controlar e influenciar. Parece entender que lhe cabe governar o mundo, mas nem sequer raciocina criativa e estrategicamente, de modo a poder interagir de forma convincente com os demais países. Não creio que se dê conta de que é impossível a qualquer país pretender ser o líder político e moral do mundo quando ele próprio manipula o Direito Internacional a seu bel-prazer. Os tratados e convenções sobre desarmamento e não-proliferação, em particular, só terão êxito se forem apoiados por todas as potências, em particular pela única "hiperpotência" (para citar Hubert de Védrine, ex-ministro das Relações Exteriores da França ), e se seus mecanismos de implementação e aplicação ("enforcement") forem devidamente reforçados, de maneira não-discriminatória.

O uso unilateral da força até pode resolver um problema ad hoc, a curto prazo, mas jamais levará a uma solução duradoura e geralmente aceitável para a comunidade internacional, que espera poder contar com práticas e políticas comuns, negociadas para o bem de todos, através de instrumentos jurídicos internacionais que garantam a verdadeira "integração" da sociedade das nações.

Os Estados Unidos não parecem entender sua responsabilidade histórica, em virtude de seu poder e influência política e econômica, por cooperar efetivamente na construção de uma arquitetura internacional sólida, ao invés de destruir a que hoje existe, cada vez mais precária. Washington também não parece compreender a razão pela qual se multiplicam focos de hostilidade contra o que os Estados Unidos representam.

Não são as instituições liberais ou a própria grandeza americana que provocam reações negativas nos quatro cantos do mundo. Há causas mais profundas, que têm a ver com contradições das políticas propostas e impostas por Washington, as quais freqüentemente representam a antítese da democracia pregada pelos Estados Unidos, como por exemplo o apoio a regimes repressivos, sempre que se trate de preservar interesses econômicos e estratégicos.

Os Estados Unidos não parecem olhar para fora, para o resto do mundo. Não parecem acreditar que talvez seja também válido celebrar autenticamente a coletividade - e não apenas o indivíduo, em detrimento da coletividade. Ou seja, celebrar uma família de nações que viva em paz e harmonia, sob um arcabouço jurídico desenvolvido consensualmente.

A globalização para além dos países ricos, por sua vez, não trouxe a prometida integração e harmonização. Erradicou, sim, culturas, línguas, práticas e costumes, transformando e às vezes "empobrecendo" sociedades pouco desenvolvidas de maneira algumas vezes irreversível.

Neste quadro, cabe indagar como reagiu o Governo brasileiro à tentativa norteamericana de desconstruir uma organização internacional que, com apenas cinco 
anos de existência, apresentava conquistas fartamente reconhecidas, para impor sua visão imperial das coisas e do mundo, neste caso específico através da demolição do indivíduo que havia sido eleito e reeleito para fazê-la florescer.

\section{A aliança pouco santa...}

Pessoalmente, minha expectativa era alta de que a reação brasileira corresponderia ao que me haviam ensinado os grandes mestres no curso de minha vida diplomática, acadêmica e profissional. Apesar de haver lutado sozinho durante cinco anos à frente da Organização, na qual serviços internacionais de inteligência procuram estar solidamente presentes, imaginava eu que, "na hora da verdade" - e porque esta seria a solução mais óbvia do ponto de vista diplomático - o Brasil agiria com a firmeza e a altivez que sempre haviam caracterizado a história do meu Itamaraty.

No início do processo, surpreendentemente, a chefia do Itamaraty, ao explicar sua falta de empenho - "apoio não exclamatório" - não foi capaz de entender a diferença básica entre um "funcionário internacional" (indivíduo formado e criado no quadro das organizações internacionais, sem vínculo profissional necessário com seu governo de origem) e um indivíduo eleito para ocupar cargo em organismo internacional (normalmente de chefia ou direção), por iniciativa de seu governo, manifestação de legítimo ato político, e como resultado de escolha eleitoral precedida de um processo de gestões e competição internacional.

Assim é que alguém se esqueceu de que meu nome havia sido apresentado pelo Governo brasileiro à comunidade internacional em 1997, que uma campanha por apoios havia sido realizada pelo Itamaraty junto aos então países membros da OPAQ para que fosse eu o candidato eleito para o posto... e que, portanto, havia uma responsabilidade do Brasil pelo desempenho do diretor-geral e por sua permanência no cargo, muito especialmente quando sob ameaça de destituição por motivos espúrios e injustificados por parte de um só Estado membro.

Em correspondência pessoal ao então chanceler brasileiro quando chegou ao meu conhecimento, por outras fontes, a iniciativa norte-americana junto ao Itamaraty para forçar-me a pedir demissão do cargo, lembrei que "havia aceito a direção da OPAQ como uma missão onde me tocava representar dignamente a melhor tradição de meu serviço diplomático". Mais adiante, em março de 2002, em correspondência também pessoal ao presidente da República - à qual, como à outra, não tive resposta - lembrei que "a comunidade internacional vê a atitude de Washington (de tentar demitir-me) claramente como uma nova demonstração do unilateralismo que os EUA pretendem impor, ao arrepio do Direito Internacional e dos mecanismos multilaterais". E que "a comunidade internacional aguarda um sinal do governo brasileiro para definir a sua ação. Se faltar uma demonstração clara de rejeição a esta iniciativa inteiramente arbitrária e contrária ao Direito Internacional, ou da defesa de minha integridade moral e profissional, como Representante do Brasil, ... provavelmente poderão ocorrer vacilações entre aqueles países que, de outra maneira, tomarão, com gosto, uma atitude de repúdio à ação norte-americana”.

Conclui lembrando que "com o apoio explícito do Brasil a minha gestão, ... os membros da OPAQ, a começar pelos países da União Européia, saberão preservar o espaço de manobra essencial à salvaguarda das instituições multilaterais" e que não 
podia "imaginar ser positivo para o meu país continuar aceitando, pelo silêncio, o que tem sido disseminado pelo governo norte-americano, ou seja, que o Brasil se estaria dobrando frente à intervenção direta, e desprovida de fundamento, dos Estados Unidos numa organização internacional" ... "Minha saída agora não poderá ter outro efeito senão o de reforçar essa indigna afirmação, tanto nacional quanto internacionalmente, razão pela qual, à falta de qualquer outro motivo e à luz de tão desnecessária humilhação para o Brasil, me vejo impedido de renunciar", foram as últimas palavras de minha carta.

Diante da pressão da opinião pública e da imprensa em geral, o silêncio de Brasília e a ineficácia e a inconseqüência dos termos das chamadas "instruções" oficiais sobre o assunto, que os arquivos do Itamaraty e dos postos no exterior protegerão para a posteridade, foram agravados pela embaraçosa situação a que fui exposto quando, em programa da televisão britânica, ouvi de John Bolton, mola mestra de minha destituição, que "even the government of Brazil, from where Mr. Bustani comes, has said that this (a iniciativa de destituir-me) is an entirely appropriate multilateral action"...

Aliás, em encontro mantido com o representante permanente dos Estados Unidos junto à $\mathrm{OPAQ}$, Donald Mahley, quando insisti em que não havia dúvida a respeito do apoio do presidente de meu país à minha manutenção à frente da $\mathrm{OPAQ}$, respondeu-me ele que eu deveria então "pedir a meu presidente que passasse esta instrução ao meu chanceler..."

Não se passaram daí muitos dias antes que eu recebesse, de fonte norte-americana, em Haia, cópia de "aide-mémoire" entregue pela Embaixada dos Estados Unidos ao Itamaraty, em Brasília, cujo texto, reproduzido a seguir, com meu grifo, é auto-explicativo:

"I am calling to express disappointment about the trend of developments in The Hague regarding the debate over the tenure of the OPCW Director-General, Mr. Bustani.

We understood that Brazilian officials would vote in support of Mr. Bustani, but not lobby on his behalf.

We understand the domestic pressures that are emerging in support of $\mathrm{Mr}$. Bustani by virtue of his nationality. However, your diplomats are not only lobbying - which we understood Brazil would not do - but are making active attempts to block action on the U.S. proposed vote of "no confidence" through procedural maneuvers.

These actions seem to us contrary to the spirit of the Secretary's (of State) March 15 conversation with Foreign Minister Lafer.

In the spirit of your agreement that each EC member be free to draw its own conclusion on Mr.Bustani's performance, we would like your agreement that we proceed quickly to a vote without further hindrance or delay."

A explicação para a "queixa” da Embaixada norte-americana em Brasília, reproduzida acima, encontra-se no fato de que alguns embaixadores brasileiros no exterior haviam decidido gestionar em meu favor com os governos junto aos quais estavam acreditados, agindo intuitivamente mesmo sem de instruções de Brasília em alguns casos, ou, em outros, desconsiderando o fato de que as comunicações que 
recebiam do Itamaraty sobre o assunto, meramente informativas, "para conhecimento exclusivo", não os instruíam a pedir apoio em meu favor, contra a proposta norte-americana para destituir-me da direção da OPAQ.

Não se havia definitivamente compreendido, na cúpula do Itamaraty, que a guerra sórdida, a campanha suja contra mim, rechaçava sobretudo o multilateralismo e a independência dos servidores civis internacionais, o que certamente não deixava, no meu caso especial, de atingir em cheio a integridade da diplomacia brasileira.

Sem a reação minimamente esperada, por parte do Itamaraty, não houve obviamente espaço para uma postura comum dos latino-americanos (exceto Cuba e México), frente a intensa e constante pressão por parte de Washington - a não ser a opção pela abstenção.

Os demais grupos regionais de países em desenvolvimento - África e Ásia - perplexos com a atitude do Brasil e do grupo latino-americano, seguiram o mesmo caminho. A União Européia e a Europa do leste acompanhavam constrangidas os Estados Unidos, uma vez que o Brasil não lhes havia pedido apoio contra a iniciativa norte-americana . A França, após gestão eficaz de Luis Inácio Lula da Silva, então candidato à presidência da República, junto a Lionel Jospin, dissociou-se de seu grupo e absteve-se. Com o apoio de apenas Rússia, China, Irã, Belarus, Cuba e México, diante de 43 abstenções e 48 votos "americanos", dava-se o maior golpe jamais realizado no campo das instituições multilaterais.

A História dirá o que já foi feito da OPAQ depois de minha partida e o que dela ainda será feito nos próximos "anos terríveis" que parece temos todos que enfrentar. No dia seguinte à minha demissão, o documento OPCW/C/SS/NAT.4, de 23 de abril de 2002, já continha a "receita" de como entendem os Estados Unidos deve ser um diretor-geral da organização.

\section{E agora, o Brasil?}

A perplexidade que se observa na comunidade internacional à luz das novas teorias de Washington e do inédito poderio político, militar e econômico dos Estados Unidos ainda não saiu da fase das discussões acadêmicas, como é o caso do interessante artigo intitulado "Power and Weakness", de Robert Kagan, publicado na Policy Review, de julho de 2002.

A chamada "Doutrina Bush", infeliz conseqüência dos acontecimentos de 11 de setembro de 2001, estabelece virtualmente uma nova confrontação entre dois mundos, agora separados por algo mais que a geografia e a economia, já prevista por Samuel Huntington, no seu livro The Clash of Civilizations.

Compreensivelmente, ainda não se vê qualquer ação coordenada de qualquer grupo de países, em busca do estabelecimento de um novo patamar de diálogo com Washington. Um diálogo que venha a proteger interesses individuais legítimos e, acima de tudo, a sobrevivência da ordem internacional estabelecida com tanta dificuldade desde 1945, bem como dos princípios de Direito Internacional tão trabalhosamente elaborados e desenvolvidos.

Não foi ainda claramente conscientizado o fato de que o poder não traz segurança e de que a segurança e a paz só virão quando as disparidades, as exclusões, as 
carências, os deslocamentos de populações forem devidamente equacionados; quando as oportunidades e as conquistas da coletividade deixarem de ser o privilégio de poucos.

Frente à necessidade de liderança no processo que permitirá explorar-se em profundidade o conceito de interdependência e pluralismo democráticos em nível internacional, não creio inadequado sugerir que o Brasil, através de sua nova administração, "saia da toca".

A atuação diplomática de um governo progressista e voltado para o interesse nacional e para a consecução de um ambiente de paz e prosperidade internacional não pode, como disse Luis Inácio Lula da Silva, em depoimento na Comissão de Relações Exteriores da Câmara de Deputados, em 19 de junho de 2002, permitir que seja jogada "nossa auto-estima para debaixo do tapete". "O Brasil precisa recuperar sua auto-estima, respeitar-se mais, falar um pouco mais grosso nas suas relações internacionais" ... porque ..."ainda não fazemos isso com a grandeza que nós, brasileiros, temos e merecemos".

ABSTRACT - IN THIS article, José Bustani, the former Director General of the Organisation for the Prohibition of Chemical Weapons (OPCW), describes the genesis of the organisation with particular focus on the importance of its non-discriminatory ideals and foundations. Despite the OPCW's recognised record of success in its first five years, with signatories increasing, Mr Bustani found himself caught in the middle of a geopolitical chess play which resulted in his removal from office. The author provides an insight into the process by which he was removed from his post after a campaign led by the United States, with ostensible collusion from elements of the Brazilian government. His account of the Organisation's young life, from the negotiation of the Convention on the Prohibition of Chemical Weapons, through to the establishment of the organisation itself in 1997 and the carrying out of its functions, up to his removal from office in April 2002, reveals the fragility of the ideals of multilateral cooperation in the 21 st century.

José Mauricio Bustani, diplomata, foi diretor-geral da Organização para a Proibição das Armas Químicas. Serviu nas embaixadas de Moscou, Viena, Nova York (junto à ONU) e Londres. 